\title{
Analysis of limit state of load resistance and reliability of masonry structures made of AAC blocks
}

\author{
Kujda Joanna ${ }^{1}$ \\ ${ }^{1}$ Rzeszow University of Technology, Dept. of Building Structures, Poznańska 2, 35-084 Rzeszow, Poland,
}

\begin{abstract}
The paper presents analysis of limit state of bearing capacity and reliability of masonry structures. A masonry made of Autoclaved Aerated Concrete $(A A C)$ with mortar for thin-layer joints was proposed. The basic calculations were carried out using the procedures available in the Eurocodes. A comprehensive analysis of the work of the masonry element was carried out. The numerical FEM model of the masonry member was made. A quantitative assessment of the safety of the structure was made by calculating the reliability index. During numerical simulation three parameter elastic-plastic model for material of masonry was used. All parameters were based on material experimental results. The analysis of masonry reliability was carried out using the probabilistic method. Masonry elements are widely used in construction, therefore their design should be based on a detailed analysis. Noteworthy is class execution of works of masonry structures and relatively high values of safety coefficient associated with it.
\end{abstract}

\section{Introduction}

Masonry structures are a type of construction that is constantly widely used in construction. We have a lot of materials available on the market to use for masonry. Using modern engineering tools, we can easily check the limit state of masonry elements. However, in the light of today's requirements, checking only the limit state is not a sufficient step in the design process. The basis in structural design lies in sufficiently safe and reliable structures' design. The safety commonly refers to the absence of hazards, but the reliability is a quantifiable value. It is important that the design process includes not only checking the condition of the limit state but also determining the reliability of the element or the whole structure.

The subject of consideration is inner masonry of the ground floor. The case in which the checked part of the masonry is placed between the door openings has been analysed. This situation commonly occurs and requires special attention. Regardless of the material selected for the masonry, its main function is to transfer loads to the lower parts of the structure and therefore it must be properly designed.

Errors in masonry structures can occur both at the design and execution stages. Practice proves that the most common causes of damage to masonry walls result from the overlap of many unfavorable factors. It is common that, mistakes made are the result of trivializing the basic implementation recommendations. Mistakes are the result of recommendations downplay the basic regulations. The design of masonry elements is based on a number of basic assumptions, for example, class execution of works and the masonry category.

Eurocod 6 [1] distinguishes 2 classes execution of works:

$\checkmark$ class A execution of works - when the masonry works are performed by a duly trained team under supervision master mortar, mortars manufactured in the factory are used, and if the mortars are produced on the construction site, the dosage of components is controlled, as well as the strength of the mortar, and the quality of works is controlled by the supervision inspector

$\checkmark$ class B execution of works - when the conditions defining the class A are not met; in this case, supervision the quality of works may be performed by a suitably qualified person authorized by the contractor.

The designer of the construction decides about the choice of class execution of works. An important factor in the security of the masonry structure is also the category of masonry elements.

The product standards define two categories of masonry elements. Marking of products in category I is possible if the probability of not meeting the declared compression strength does not exceed 5\%. If the probability is higher, the product should be included in category II. Masonry elements can be classified in category I, if the production is additionally controlled by independent certification bodies, and in the production plant a factory production control book is kept.

In the paper, checking the limit state of masonry subjected to the compressive force was conducted. These analyses were made using procedures included in the EC6 [1]. The calculations were supplemented by

* Corresponding author: j.kujda@prz.edu.pl 
determining the reliability index and numerical analysis of the tested masonry.

\section{Reliability}

Considering the development of the methods of structural analysis and economics, it is very important to comprehensively evaluate the design including its quantitative safety. Because of the natural variability of the masonry structures, the information on its real mechanical properties should be obtained from in situ studies. The relevant input data including information on the actual properties of the materials and the effects of interactions should be taken into account. Such a data package allows for an accurate analysis of the masonry structure, first of all a quantitative safety assessment. The use of probabilistic design to evaluate masonry structures enables more economical approach.

Reliability is the most important requirement for structures. In design, every parameter is uncertain to some extent. Structures have to be reliable according to load bearing capacity as well as serviceability. Reliability of a structure is a measure that can be described by a formula:

$$
Z=N_{R}-N_{E}
$$

$N_{R}$ - effect of resistance ;

$N_{E}$ - effect of load.

The failure probability can be computed by probabilistic methods such as FORM (First Order Reliability Method), SORM (Second Order Reliability Method) or Monte Carlo - simulation. The last method most often requires the use of advanced software generating a large number of simulations.

The first step in reliability analysis is the adoption of basic variables as random variables. Based on the results of statistical surveys, it is usually assumed in literature and design standards that the basic impacts on buildings can be considered as random variables with distributions and variability coefficients $v[2,3,4]$ :

- dead load and quasi - dead load - normal distribution (N), $v=0,02 \div 0,10$;

- long-term variables - gamma distribution $(\Gamma)$, $v=0,18 \div 0,40$;

- short-term variables - exponential distribution (E), $v=0,20 \div 0,80$;

- snow, wind - Gumbel's distribution (G), $v=0,40 \div 1,00$;

The properties of materials are described by specifying a characteristic value which corresponds to a given quantile of the adopted statistical distribution of a specific material or product property. In certain circumstances, the nominal value is taken as the characteristic value.

Properties of masonry materials can be considered as random variables with coefficients of variation $v=0,05 \div 0,11[2]$.
The average values and coefficients of variation required in the design procedure are calculated assuming that the defined characteristic quantities are random variables described in normal distribution:

- by the average value of variables whose characteristic value is defined as the lower quantile (strength of materials):

$$
M_{x i d}=X_{k i d} /(1-1,645 v)
$$

$M_{\text {xid }}$ - average value of the lower limit;

$X_{k i d}$ - characteristic value, defined as the lower quantile; $v$ - coefficient of variation

- by the average value of variables whose characteristic value is defined as the upper quantile (load):

$$
M_{x i g}=X_{k i g} /(1+1,645 v)
$$

$M_{x i g}$ - average value of the upper limit;

$X_{k i g}$ - characteristic value, defined as the upper quantile; $v$ - coefficient of variation

The coefficient of variation is the ratio of the standard deviation $\sigma$, which can be taken from the literature data to the mean value:

$$
v=\sigma / M_{x i d}==\sigma / M_{x i g}
$$

While construction safety is an immeasurable feature, reliability can be measured. The measure of reliability is the reliability index $\beta$ by Cornell. The major advantage rely on that only the mean and standard deviation of the basic variables need to be known. Eurokod [5] gives the recommended minimum values of the reliability index for the limit states depending on the reference period and the reliability class of the structure. For example, the value of the reliability index for the 50-year observation period and the reliability class $\mathrm{RC} 2$ is $\beta_{\text {lim }}=3.8$. The reliability index $\beta$ is an alternative to the probability of failure $P_{f}$ in determining the safety of the structure.

The algorithm for determining the reliability index using the FORM probabilistic method is as follows:

- the functions of the limit state should be formulated and the parameters of distributions of random variables occurring in the function of the limit state should be determined;

- find a design point taking the initial values for variables (assuming average values), the boundary state equation should be solved in relation to the remaining random variable; thanks to this, the starting point will belong to the border of the failure area;

- calculate the values of reduced variables corresponding to the design point;

- partial derivatives of the limit state function should be determined relative to the reduced random variables;

- calculate the approximation of the reliability index using appropriate formulas;

- calculate the sensitivity coefficients;

- a new design point should be set in the space of reduced random variables ;

- specify the design point in the starting coordinates; 
- calculate the value of a random variable by solving the boundary state equation;

- repeat steps until a convergence of the reliability index $\beta$ values and the coordinates point of the design.

\section{The analysed member of masonry}

\subsection{Material}

The performed analysis used blocks made from Autoclaved Aerated Concrete $(A A C)$ of one of polish manufacturer. The masonry units $(600 \mathrm{~kg} / \mathrm{m} 3$ type $)$ had dimensions $590 \quad x \quad 180 \times 240 \quad \mathrm{~mm}$, characteristic compressive strength $f_{b}=4,0 \mathrm{MPa}$. System mortar for thin-layer joints was used. Exact research on this type of elements is presented in the paper [6].

\subsection{Description of the analysed structure}

The analysed masonry structures is located on the ground floor of a two-story building. The height of the storey in the axes of the ceilings is $2,95 \mathrm{~m}$. A fragment of the analysed masonry is located between the $1 \mathrm{~m}$ wide door openings. The span of the slabs reaching the wall is $4,80 \mathrm{~m}$ and $5,40 \mathrm{~m}$. The geometry of masonry and the surface of the load interaction that the wall takes over is shown in Fig. 1.

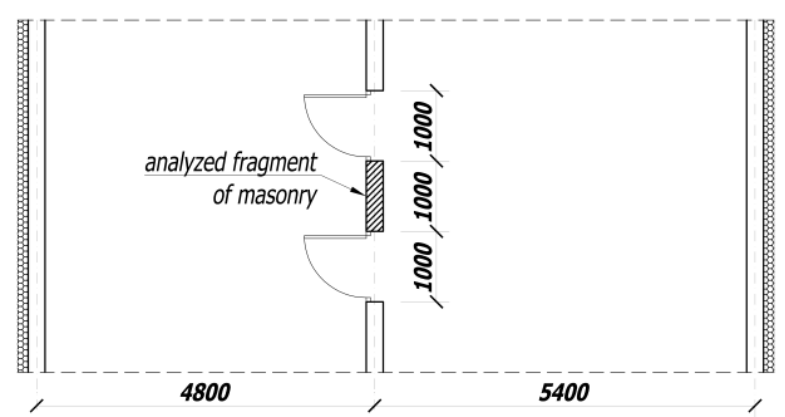

Fig. 1. The geometry of masonry and the surface of the load interaction

\section{Case study}

\subsection{Limit state by EC6}

The following condition was used to check the condition of limit state of the compression masonry load [1]:

$$
N_{\mathrm{Ed}} \leq N_{R d}
$$

$N_{\text {Ed }}$ - design load in the masonry

$N_{\mathrm{Rd}}$ - design compressive load capacity of masonry

The framework model suggested by Eurocode for determining the load-bearing capacity of the masonry was used. The wall was therefore analyzed at three points : at the top - point ' 1 ', in the middle - point ' $m$ ', at the bottom - point ' 2 '.

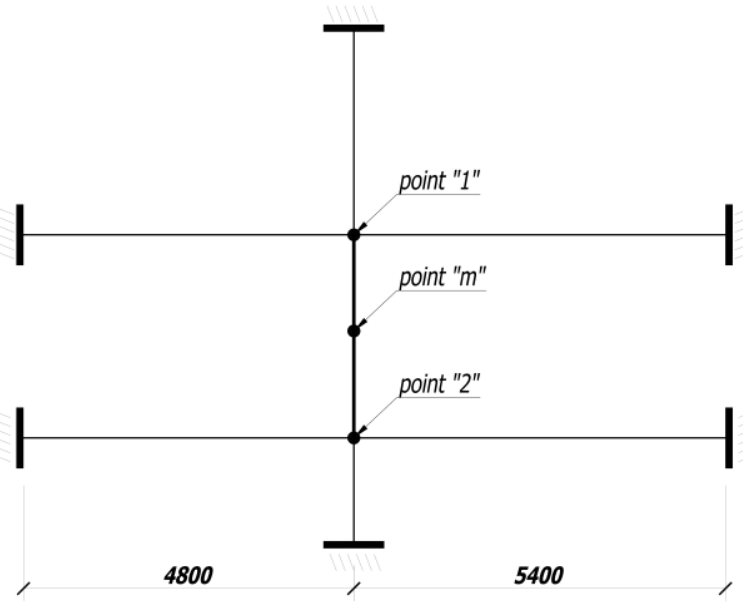

Fig. 2. The framework model of masonry

The dead load of the analysed masonry comes from the roof of the building, ceilings, masonry of higher storeys and reinforcement perimeter beam $\left(G_{k, j}\right)$. The variable load comes from the sum of the live load and the load on the partition walls $\left(\mathrm{Q}_{\mathrm{k}, 1}\right)$ and comes from snow on the roof $\left(Q_{k, 2}\right)$. The characteristic values of load at individual points of the masonry are presented in Table 1 .

Table 1. The characteristic values of load of the masonry

\begin{tabular}{|c|c|c|}
\hline \multicolumn{2}{|c|}{ Load } & Value [kN] \\
\hline \multirow{3}{*}{$\mathrm{G}_{\mathrm{k}, \mathrm{j}}$} & $\mathrm{G}_{\mathrm{k} 1}$ & 132,30 \\
\cline { 2 - 3 } & $\mathrm{G}_{\mathrm{km}}$ & 135,01 \\
\cline { 2 - 3 } & $\mathrm{G}_{\mathrm{k} 2}$ & 137,72 \\
\hline \multicolumn{2}{|c|}{$\mathrm{Q}_{\mathrm{k}, 1}$} & 38,76 \\
\hline \multicolumn{2}{|c|}{$\mathrm{Q}_{\mathrm{k}, 2}$} & 5,71 \\
\hline
\end{tabular}

To calculate the design values of load, a combination according to the EN 1990 [5] was used.

$N_{E d}=\Sigma \xi \cdot \gamma_{G, j} \cdot G_{k, j}+\gamma_{Q, 1} \cdot Q_{k, 1}+\gamma_{Q, 2} \cdot \psi_{0,2} \cdot Q_{k, 2}$

The following partial factors for the effect of load were applied:

$\xi=0,85 ; \gamma_{G, j}=1,35 ; \gamma_{Q, 1}=1,50 ; \gamma_{Q, 2}=1,50 ; \psi_{0,2}=0,50$

The design values of load at individual cross sections of the masonry are presented in Table 2 .

Table 2. The design values of load of the masonry

\begin{tabular}{|c|c|}
\hline Point & Value [kN] \\
\hline $\mathrm{N}_{1 \mathrm{~d}}$ & 223,58 \\
\hline $\mathrm{N}_{\mathrm{md}}$ & 227,25 \\
\hline $\mathrm{N}_{2 \mathrm{~d}}$ & 230,91 \\
\hline
\end{tabular}

Design value of compressive load capacity of the masonry was determined from the formula:

$$
N_{R d}=\phi \cdot A \cdot f_{d}
$$

$\phi$ - reduction coefficient ;

$A$ - masonry area; 
$f_{d}$ - design compressive strength of masonry.

Design compressive strength of masonry using Eurocode 6 [1] was assumed. Characteristic compressive strength of masonry of Autoclaved Aerated Concrete with system mortar for thin-layer joints is determined by formula:

$$
f_{k}=K f_{b}^{0,85}
$$

$K$ - coefficient, for Autoclaved Aerated Concrete with system mortar for thin-layer joints $K=0,75$;

$f_{b}$ - compressive strength of Autoclaved Aerated Concrete, $f_{b}=4,0 \mathrm{MPa}$.

$f_{k}=0,75 \cdot 4,0^{0,85}=2,44 \mathrm{MPa}$

Design compressive strength of masonry is determined by formula:

$$
\begin{aligned}
& f_{d}=f_{k} / \gamma_{M} \\
& \gamma_{M}=\gamma_{m} \cdot \gamma_{R d}
\end{aligned}
$$

$\gamma_{m}-$ partial factors, for Autoclaved Aerated Concrete and class "B" execution of works, $\gamma_{m}=2,0$

$\gamma_{R d}$ - factor, for masonry area $A=0,24 \mathrm{~m}^{2}$, $\gamma_{R d}=1,15$

$f_{d}=1,06 \mathrm{MPa}$

Coefficient taking into account the slenderness and the size of the eccentric - $\phi$ - espectively at the top $\left(\phi_{1}\right)$, middle $\left(\phi_{m}\right)$, and bottom $\left(\phi_{2}\right)$ of masonry are summarized in Table 3.

Table 3. Value of the coefficient " $\phi$ "

\begin{tabular}{|c|c|}
\hline Point & Value $[\mathbf{k N}]$ \\
\hline$\phi_{1}$ & 0,86 \\
\hline$\phi_{\mathrm{m}}$ & 0,82 \\
\hline$\phi_{2}$ & 0,88 \\
\hline
\end{tabular}

$N_{R d, 1}=218,71 \mathrm{kN}$

$N_{R d, m}=209,06 \mathrm{kN}$

$N_{R d, 2}=223,72 \mathrm{kN}$

Conditions for the limit state for the masonry:

$N_{l d} / N_{R d, I}=223,58 / 218,71=1,02$

$N_{m d} / N_{R d, m}=227,25 / 209,06=1,09$

$N_{2 d} / N_{R d, 2}=230,91 / 223,72=1,03$

At each cross section, the load capacity of masonry has been insufficient. In order to verify the calculations, further analyses were carried out in points 4.2 and 4.3.

\subsection{Numerical analysis FEM}

An alternative solution to laborious and expensive experimental research may be numerical analysis. Numerical model of masonry was created using software for FEM (Finite Elements Method). The geometry of the 3D masonry frame model has been created in the GID program [7]. Calculations were carried out in
ATENA 3D [8]. ATENA is a user friendly software for nonlinear analysis. The program is dedicated to reinforced concrete structures but it can also be used for analysis of structures made of other materials, for example masonry. To describe the material used in the model used material model 3D Non Linear Cementitious 2 [9]. Extensive research on this type of Autoclaved Aerated Concrete elements is presented in the paper [6]. Parameters of AAC blocks are included in Table 4.

Table 4. Material properties of ACC blocks [6]

\begin{tabular}{|l|l|}
\hline Parameter & \\
\hline Elastic modulus E [MPa] & $2.204 \mathrm{E}+03$ \\
\hline Poisson's ratio $\mu[-]$ & 0.200 \\
\hline Tensile strength $\mathrm{f}_{\mathrm{t}}[\mathrm{MPa}]$ & $4.30 \mathrm{E}-01$ \\
\hline Compressive strength $\mathrm{f}_{\mathrm{c}}[\mathrm{MPa}]$ & $-2.97 \mathrm{E}+00$ \\
\hline Specific fracture energy $\mathrm{G}_{\mathrm{f}}[\mathrm{MN} / \mathrm{m}]$ & $1.07 \mathrm{E}-05$ \\
\hline Plastic strain at strength $\mathrm{f}_{\mathrm{c \varepsilon CP}}[-]$ & $-4.18 \mathrm{E}-04$ \\
\hline Critical compressive displacement wd [m] & $-5.0000 \mathrm{E}-04$ \\
\hline $\begin{array}{l}\text { Reduction of compressive strength due to } \\
\text { cracks } \mathrm{f}_{\mathrm{c}-\text { lim }}[-]\end{array}$ & 0,8 \\
\hline Crack shear stiffness factor $\mathrm{S}_{\mathrm{F}}[-]$ & 20.0 \\
\hline Maximal aggregate size [m] & 0.0200 \\
\hline $\begin{array}{l}\text { Eccentric defining the shape of the failure } \\
\text { surface [-] }\end{array}$ & 0,5 \\
\hline Specific material weight $\left[\mathrm{MN} / \mathrm{m}^{3}\right]$ & $6.000 \mathrm{E}-03$ \\
\hline Coefficient of thermal expansion $\alpha[1 / \mathrm{K}]$ & $1.200 \mathrm{E}-05$ \\
\hline Fixed crack mode coefficient $[-]$ & 1.0 \\
\hline
\end{tabular}

Individual ACC blocks were modeled as separate blocks. The geometry corresponding to the $3 \mathrm{D}$ masonry frame model has been generated. The connection between the blocks was created by modeling "contact volume". The connection parameters between the blocks are shown in Table 5.

Table 5. Connection properties between the blocks [6]

\begin{tabular}{|l|l|}
\hline Parameter & \\
\hline Tensile strength $\mathrm{f}_{\mathrm{t}}[\mathrm{MPa}]$ & $2.900 \mathrm{E}-01$ \\
\hline Cohesion c & $3.058 \mathrm{E}-01$ \\
\hline Friction coefficient $\mathrm{t}_{\mathrm{g}} \phi$ & $6.261 \mathrm{E}-01$ \\
\hline $\begin{array}{l}\text { Specific fracture energy at transverse GII } \\
{[\mathrm{MN} / \mathrm{m}]}\end{array}$ & $-1.07 \mathrm{E}-05$ \\
\hline
\end{tabular}

The modeling procedure also included the selection of the correspondingly convergent finite element mesh and the setting of non-linear analysis parameters. The Newton-Raphson method was chosen to solve differential equations of nonlinear analysis. The geometry of model FEM of masonry is shown in Fig 3. 


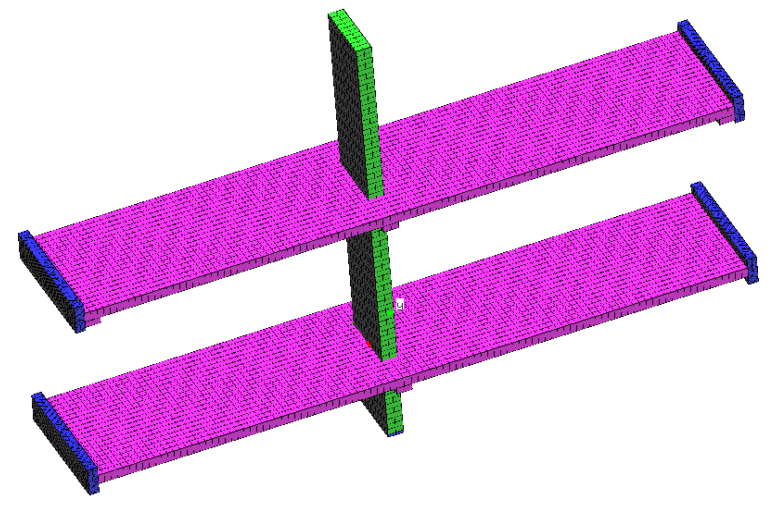

Fig. 3. The geometry of model FEM of masonry

In order to compare the effect of load with compressive load capacity of masonry in the model, characteristic load values were compiled for the model. In order to best imitate the behavior of the wall, the initial eccentricity derived from the inaccuracy of the masonry. Masonry deformation under load as well as appearing compressive stresses in the ground floor wall were analyzed. Masonry deformation are shown in the Fig. 4.
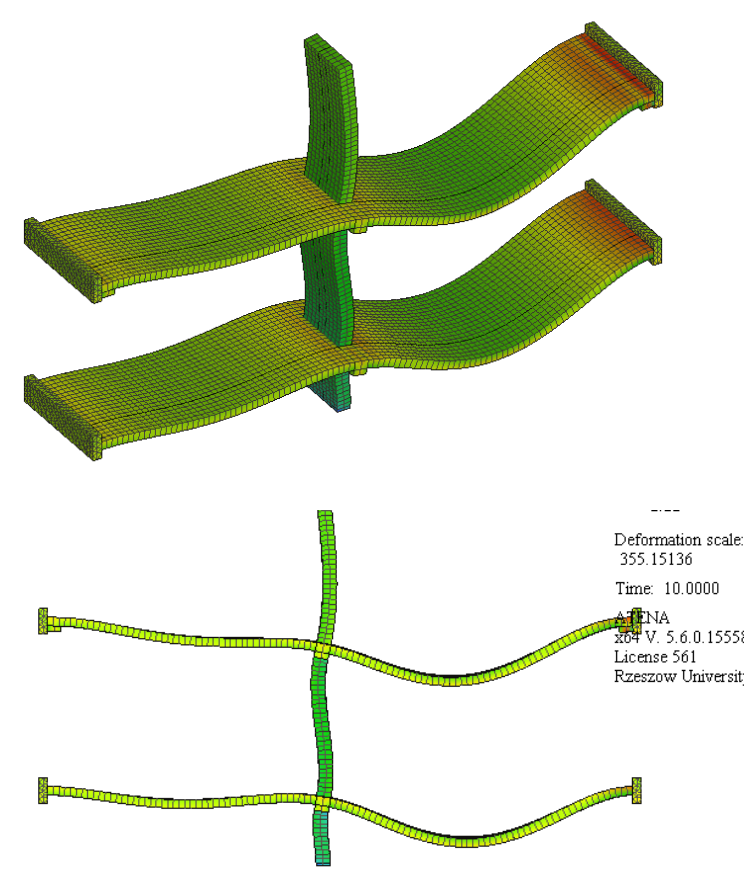

Fig. 4. Masonry deformation in model FEM

The compressive stresses obtained in the ground floor masonry are shown in the Fig. 5.

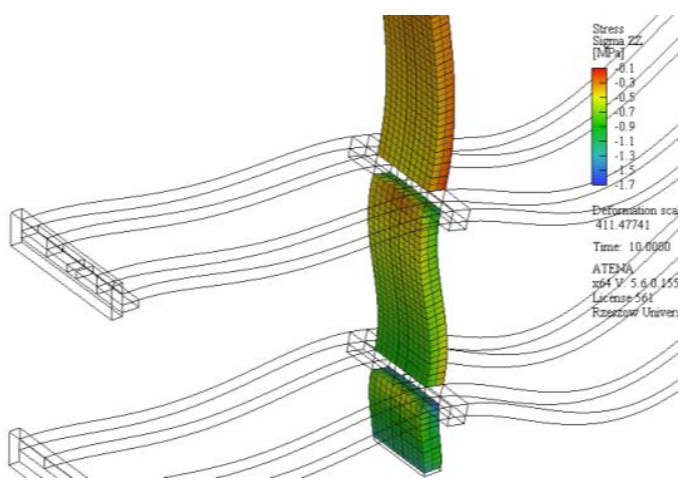

Fig. 5. The compressive stresses obtained in the ground floor masonry

The maximum value of the compressive stress calculated occured appearing in the ground floor masonry was: 1,18 $\mathrm{MPa}$. Numerical analysis of the masonry fragment showed that the masonry load condition was not exceeded. Stresses appearing in blocks of the masonry at no point reached the mean values resulting from experimental research. Therefore, there was no excessive bending of the masonry and cracks.

\subsection{The probability of ULS}

The final stage of the masonry member analysis was to conducting a simulation to determine the reliability index. Reliability index of the masonry wall of structure was calculated using probabilistic method. The limit state function for the masonry was determined:

$$
Z=\left(1-2 e_{i} / t\right) \cdot t \cdot f_{m} \cdot l-\left(\Sigma G_{m, j}+\Sigma Q_{m, j}\right)
$$

For individual random variables, density functions, average values and standard deviations were determined.

Load:

$\checkmark$ dead load: $\Sigma G_{k, j}=137,72 \mathrm{kN}$,

$v_{G}=10 \%$,

$\Sigma G_{m, j}=\Sigma G_{k, j} /\left(1+1,645 v_{G}\right)=137,72 /(1+1,645 \cdot 0,10)$

$=118,27 \mathrm{kN}$

$\checkmark$ live load: $\Sigma Q_{k, j}=44,47 \mathrm{kN}$

$v_{Q}=20 \%$,

$\Sigma Q_{m, j}=\Sigma Q_{k, j} /\left(1+1,645 v_{Q}\right)=44,47 /(1+1,645 \cdot 0,20)$

$=33,46 \mathrm{kN}$

$\Sigma G_{m, j} ; \Sigma Q_{m, j}$ - mean values

$v_{G}, v_{Q}$ - coefficient of variation

Compressive strength of masonry:

$\checkmark$ characteristic value: $f_{k}=2,44 \mathrm{MPa}$,

$v_{m}=19 \%$,

$f_{m}=f_{k} /\left(1-1,645 v_{m}\right)=2,44 /(1-1,645 \cdot 0,19)$

$=3,54 \mathrm{MPa}$

$f_{m}$ - mean value

Geometrical dimensions:

$\checkmark$ masonry thickness: $t=240 \mathrm{~mm}, v_{t}=5 \%$, 
$\checkmark$ eccentricity: $e_{i}=0,1 \cdot t=0,1 \cdot 0,24=24 \mathrm{~mm}$, $v_{e}=5 \%$,

$\checkmark$ masonry area: $l=1000 \mathrm{~mm}, v_{l}=0 \%$,

Random variables, density functions, average values and standard deviations of random variables are summarized in Table 6.

Table 6. Information about random variables

\begin{tabular}{|l|c|c|c|}
\hline \multicolumn{1}{|c|}{$\begin{array}{c}\text { Random } \\
\text { variables }\end{array}$} & $\begin{array}{c}\text { Density } \\
\text { functions }\end{array}$ & $\begin{array}{c}\text { Average } \\
\text { values }\end{array}$ & $\begin{array}{c}\text { Standard } \\
\text { deviations }\end{array}$ \\
\hline$t[\mathrm{~mm}]$ & Normal & 240 & 12,00 \\
\hline$l[\mathrm{~mm}]$ & Deterministic & 1000 & - \\
\hline$f_{m}\left[\mathrm{~N} / \mathrm{mm}^{2}\right]$ & Normal & 3,54 & 0,67 \\
\hline$e_{i}[\mathrm{~mm}]$ & Normal & 24 & 1,20 \\
\hline$\Sigma \mathrm{Gm}_{\mathrm{m}, j}[\mathrm{kN}]$ & Normal & 118,27 & 11,83 \\
\hline$\Sigma Q_{m, j}[\mathrm{kN}]$ & Normal & 33,46 & 6,69 \\
\hline
\end{tabular}

An example of the distribution of the random variable $f_{m}$ is shown in Figure 6.

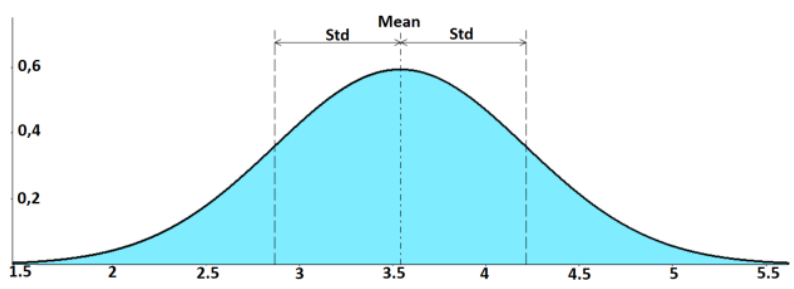

Fig. 6. An example of the distribution of the random variable $f_{m}$

The data presented were used to determine the reliability of the structure using the FORM probabilistic method. Obtained by the probabilistic method, after 63 iterations, the value of the reliability index $\beta=4,05$.

This value meets the requirements for member resistance class RC2 and 50 years.

As the result the probability of failure was calculated:

$P_{f}=2,526 E-05(\beta=4,05)$

$P_{f}=2,526 E-05(\beta=4,05)>P_{f d}=7,23 E-05(\beta=3,80)$

The analysis performed using the probabilistic method confirmed that the condition of reliability is met.

\section{Conclusions}

The analyses carried out showed that in the case of the procedure proposed in Eurocod 6 [1] checking the load bearing capacity of the masonry, the conditions were not met at any point in the wall. It is worth emphasizing, however, that rigorous approach was applied. During the determination of the safety factor of the masonry element, reference was made to class B of carrying out works. Such an approach generates a higher value of the safety factor and, consequently, less load bearing capacity. However, this is a safer approach. Safety verification was carried out in the further stages of the masonry member analysis. The numerical analysis of the masonry fragment showed no risk resulting from exceeding the load capacity of the masonry. The maximum value of the compressive stress appearing in the ground floor masonry was: $1,18 \mathrm{MPa}$. This value does not exceed the average value of the compressive masonry resistance $f_{m}=3,54 \mathrm{MPa}$. Therefore, there was no excessive bending of the masonry and no cracks. The model was made taking into account the value of the initial eccentricity derived from the inaccuracy of the masonry.

The confirmation of the FEM analysis was calculating using FORM probabilistic method to determine the quantitative measure of the safety of the structure. After 63 iterations, convergence of the process iteration was achieved and the value of the reliability index at the level 4,05 was set. The value obtained meets the requirements for member resistance class RC2. The analyzes show how important the comprehensive design procedure is.

\section{References}

1. EN 1996-1-1:2004 Eurocode 6: Design of masonry structures - Part 1-1: General rules for reinforced and unreinforced masonry structures. 2004 CEN.

2. Sz. Woliński, Calibration of partial coefficients for existing structures, Scientific notebooks, PRz 2011, in Polish.

3. Sz. Woliński, K. Wróbel, Reliability of building structures, Rzeszow, in Polish, 2001.

4. Sz. Woliński, Fundamentals of Designing Structures in General Construction, ed. Lichołai Lech, PWN t 3, pp. 112-146, in Polish 2011

5. EN 1990:2002 Eurocode - Basis of structural design. 2002 CEN.

6. Ł. Drobiec, R. Jasiński, W. Mazur, Research of mechanical properties of lintels made of Autoclaved Aerated Concrete under different way of load, Building Materials, 9 (2015), pp. 114-116.

7. V. Cervenka, L. Jendele, J. Cervenka, ATENA Program Documentation Part 8 User's Manual for ATENA-GID, Copyright 2000-2017 Červenka Consulting s.r.o., Prague, July 24, 2017.

8. V. Cervenka, L. Jendele, J. Cervenka, ATENA Program Documentation Part 1 Theory. Copyright 2000-2017 Červenka Consulting s.r.o., Prague, July 24, 2017.

9. J. Cervenka, V.K. Papanikolaou, Three dimensional combined fracture-plastic material model for concrete, International Journal of Plasticity, 24 (2008), pp. 2192-2220. 